\title{
PPAR $\alpha$ deficiency reduces insulin resistance and atherosclerosis in apoE-null mice
}

\author{
Karen Tordjman, ${ }^{1}$ Carlos Bernal-Mizrachi, ${ }^{1}$ Laura Zemany, ${ }^{1}$ Sherry Weng, ${ }^{1}$ \\ Chu Feng, ${ }^{1}$ Fengjuan Zhang, ${ }^{1}$ Teresa C. Leone, ${ }^{1}$ Trey Coleman, ${ }^{1}$ \\ Daniel P. Kelly, ${ }^{1,2}$ and Clay F. Semenkovich ${ }^{1,3}$ \\ ${ }^{1}$ Department of Medicine and the Center for Cardiovascular Research, \\ ${ }^{2}$ Department of Molecular Biology and Pharmacology, and \\ ${ }^{3}$ Department of Cell Biology and Physiology, Washington University School of Medicine, St. Louis, Missouri, USA \\ Address correspondence to: Clay F. Semenkovich, Division of Atherosclerosis, Nutrition, and Lipid Research, \\ Washington University School of Medicine, Campus Box 8046, 660 South Euclid Avenue, St. Louis, Missouri 63110, USA. \\ Phone: (314) 362-4454; Fax: (314) 747-4477; E-mail: semenkov@im.wustl.edu.
}

Karen Tordjman and Carlos Bernal-Mizrachi contributed equally to this work.

Received for publication October 6, 2000, and accepted in revised form March 13, 2001.

PPAR $\alpha$ is a ligand-dependent transcription factor expressed at high levels in the liver. Its activation by the drug gemfibrozil reduces clinical events in humans with established atherosclerosis, but the underlying mechanisms are incompletely defined. To clarify the role of PPAR $\alpha$ in vascular disease, we crossed PPAR $\alpha$-null mice with apoE-null mice to determine if the genetic absence of PPAR $\alpha$ affects vascular disease in a robust atherosclerosis model. On a high-fat diet, concentrations of atherogenic lipoproteins were higher in PPAR $\alpha^{-/-} \mathrm{apoE}^{-/-}$than in PPAR $\alpha^{+/+} \mathrm{apoE}^{-/-}$mice, due to increased VLDL production. However, en face atherosclerotic lesion areas at the aortic arch, thoracic aorta, and abdominal aorta were less in PPAR $\alpha$-null animals of both sexes after 6 and 10 weeks of high-fat feeding. Despite gaining as much or more weight than their PPAR $\alpha^{+/+} \mathrm{apoE}^{-/-}$littermates, $\mathrm{PPAR}^{-/-} \mathrm{apoE}^{-/-}$ mice had lower fasting levels of glucose and insulin. PPAR $\alpha$-null animals had greater suppression of endogenous glucose production in hyperinsulinemic clamp experiments, reflecting less insulin resistance in the absence of PPAR $\alpha$. PPAR $\alpha^{-/-} \mathrm{apoE}^{-/-}$mice also had lower blood pressures than their $\mathrm{PPAR}^{+/+} \mathrm{apoE}^{-/-}$littermates after high-fat feeding. These results suggest that PPAR $\alpha$ may participate in the pathogenesis of diet-induced insulin resistance and atherosclerosis.

J. Clin. Invest. 107:1025-1034 (2001).

\section{Introduction}

Vascular disease is the most common cause of death in people with type 2 diabetes, which is characterized by obesity, hyperglycemia, hyperinsulinemia, hypertension, and dyslipidemia. Insulin resistance is associated with each of these disorders (1). PPARs, ligand-activated nuclear transcription factors (2), represent a potential biologic link between insulin resistance and atherogenesis. Fibrates and thiazolidinediones, drugs commonly used to treat people with diabetes and vascular disease, are respective ligands for two of these receptors, PPAR $\alpha$ and PPAR $\gamma$.

PPAR $\alpha$ is present at high levels in the liver (3), where its activation increases fatty acid oxidation and alters apolipoprotein expression. PPAR $\gamma$ is present at high levels in adipose tissue (4) where its activation increases lipid storage and enhances insulin sensitivity through poorly understood mechanisms. PPARs are found at multiple other sites including the kidney, a key determinant of blood pressure, and the vascular wall (5), a site commonly affected by insulin resistance $(6,7)$.

Atherosclerosis is characterized by the abnormal accumulation of lipid in blood vessels. Functional binding sites for PPARs are found in the promoters for several genes involved in cellular lipid accumulation, including lipoprotein lipase (LPL) (8), the scavenger receptor CD36 (9), fatty acid transport protein (10), and long-chain acylCoA synthase (11). LPL and CD36 are expressed in the vascular wall. Mice deficient in LPL (12) or CD36 (13) are resistant to atherosclerosis. These findings raise the possibility that PPARs and their natural ligands may participate in the progression of atherosclerotic lesions. Conflicting data $(9,14)$ address the capacity of PPARs to promote the development of foam cells, essential participants in the atherosclerotic process. Gemfibrozil, a PPAR $\alpha$ activator, decreases vascular events in humans with established atherosclerosis (15), and PPAR $\gamma$ ligands decrease lesion formation in male (but not female) mice (16). These findings raise the possibility that systemic effects of PPAR activators overcome any potential adverse effects of these agents at the vessel wall. Defects in PPAR signaling have been implicated in the development of hypertension $(17,18)$. Hepatic activation of PPAR $\alpha$ affects production of fibrinogen and plasminogen-activator inhibitor-1 and improves dyslipidemia (19). PPAR $\alpha$ agonists may decrease adiposity and increase insulin sensitivity (20). Collectively, these data suggest that the absence of PPAR $\alpha$ would increase lipids 
and blood pressure, decrease insulin sensitivity, and promote atherosclerosis.

In this study, we address the role of PPAR $\alpha$ in dietinduced atherosclerosis and insulin resistance by crossing PPAR $\alpha$-null mice (21) with apoE-deficient mice (22). High-fat-fed PPAR $\alpha$-null mice have higher levels of atherogenic lipoproteins, but surprisingly, are more responsive to insulin, have lower blood pressures, and develop less atherosclerosis.

\section{Methods}

Animals. PPARo-null mice (21) were crossed with apoE-null mice (22) in the C57Bl/ 6 background. Once PPAR $\alpha /$ apoE double-null mice were generated, these animals were again crossed with apoE-null mice in the $\mathrm{C} 57 \mathrm{Bl} / 6$ background, and offspring were bred to generate PPAR $\alpha^{-/}$apoE $^{-/-}$mice and PPAR $\alpha^{+/+}$apoE $^{-/-}$littermates that were used as controls. We studied large numbers of these littermates with the same C57Bl/ 6 background of approximately $75 \%$. Identical atherosclerosis results were seen in mice with a C57Bl/ 6 background of approximately $50 \%$ (see Figure $5 \mathrm{a}$ ). Doubleknockout founder mice were genotyped by Southern blotting and multiplex PCR. Offspring were genotyped by PCR techniques alone. Mice were weaned to a rodent diet with a total fat content of $6 \%$ at 21 days of age. At 8 weeks of age, animals were started on a Western diet containing $0.15 \%$ cholesterol and providing $42 \%$ calories as fat (TD 88137; Harlan Teklad, Madison, Wisconsin, USA). In some experiments, animals were fed the Western diet containing the PPAR $\alpha$ agonist WY-14,643 (TD 00591; Harlan Teklad). For these experiments, WY-14,643 was shipped directly from the supplier (Biomol Research Laboratories, Plymouth Meeting, Pennsylvania, USA) to Harlan Teklad and incorporated into diet TD88137 at a concentration of $0.1 \%(w t / w t)$.

Analytical procedures. Mice were fasted for 4 hours before blood drawing. On the same day as blood drawing, serum was assayed for triglycerides, cholesterol, glucose, and nonesterified fatty acids (NEFA), as described $(12,23)$. Insulin was assayed by radioimmunoassay (Linco Research Inc., St. Charles, Missouri, USA). Levels of lipoproteins were analyzed by fast-protein liquid chromatography as described $(12,23)$.

Lipoprotein metabolism. VLDL turnover was determined using radiolabeled VLDL as described by Weinstock et al. (24). PPAR $\alpha^{+/+} \mathrm{apoE}^{-/-}$mice were injected with $200 \mu \mathrm{Ci}\left[9,10-{ }^{3} \mathrm{H}\right]$ palmitic acid in corn oil. Fortyfive minutes later, serum was isolated and subjected to centrifugation overnight at $95,700 \mathrm{~g}$ using a Beckman TL55 rotor and a TL-100 ultracentrifuge. Radiolabeled VLDL was isolated and injected in fasting mice followed by collection of serum at $0.5,1,2,5$, and 20 minutes. Triglyceride production rates were determined by chemically inhibiting intravascular lipolysis (25). Triton WR 1339 was made 4\% (vol/vol) in PBS (pH 7.4). Baseline triglycerides were measured in fasted mice, animals were injected with Triton WR 1339 at a dose of $100 \mathrm{mg} / \mathrm{kg}$, then serum triglycerides were determined 15 and 30 minutes later.

Determination of LPL activity in postheparin plasma and macrophages. For postheparin LPL, mice were injected intraperitoneally with $200 \mathrm{U}$ of sodium heparin as described (26). Thirty minutes later, venipuncture was performed, plasma was isolated, and LPL enzyme activity was assayed as described (27). Macrophages were isolated as described by Febbraio et al. (13). Mice were injected intraperitoneally with a $4 \%$ solution of thioglycolate on day 1 . On day 5 , peritoneal macrophages were isolated, washed, counted, and plated in DMEM plus $10 \%$ FBS. Cells were fed on day 6 . On day 7 , cells were washed and incubated in DMEM plus 0.5\% BSA for 4 hours, followed by incubation with $0.5 \mathrm{U} / \mathrm{ml}$ heparin, collection of medium, and subsequent determination of LPL activity.

Intimal lesion quantification. Lesion area was determined as described $(12,23)$. Images of pinned aortas were captured using a digital camera and analyzed using an image-processing program. Data are reported as the percentage of involvement of the intimal surface area for the arch (extending from the aortic valve to a point just distal to the left subclavian artery), the thoracic aorta (extending to the last intercostal artery), and the abdominal aorta (extending to the ileal bifurcation).

Immunocytochemistry. Hearts were frozen in TissueTek OCT compound (Sakura Finetek, Torrance, California, USA). Frozen sections at the proximal aorta were fixed with acetone, and endogenous peroxidase activity was quenched with $0.6 \%$ hydrogen peroxide in methanol. Slides were blocked for 45 minutes at room temperature in PBS with $1 \%$ BSA, $0.3 \%$ Triton X-100, and 5\% horse serum (S-2000; Vector Laboratories, Burlingame, California, USA). Slides were incubated for 60 minutes at room temperature with a 1:50 dilution of goat polyclonal anti-PPAR $\alpha$ Ab (SC-1982; Santa Cruz Biotechnology Inc., Santa Cruz, California, USA), rinsed, then incubated with a 1:200 dilution of biotinylated anti-goat Ab (BA-9500; Vector Laboratories). Slides were rinsed again, sequentially incubated with streptavidin peroxidase followed by aminoethyl carbazole substrate solution, then rinsed and counterstained with hematoxylin.

Quantitative RT-PCR-based gene expression analyses. Animals were fed a Western diet plus 0.1\% WY-14,643 for 1 or 4 weeks, then aortas (from the origin to the iliac arteries) were isolated, weighed, and used to prepare RNA using guanidinium isothiocyanate and sedimentation through cesium chloride. Hepatic RNA was also prepared from each animal. Aortas from three to seven animals were pooled for each RNA analysis. There was no effect of genotype on aortic weights or RNA yields. Monocyte chemotactic protein (MCP-1), LPL, CD36, and GAPDH mRNA levels were quantified in the aorta, and acyl CoA oxidase (ACO) and GAPDH mRNA were determined in the liver. After treatment with DNase, 1 $\mu \mathrm{g}$ of total RNA was reverse transcribed using Superscript II (Life Technologies, Rockville, Maryland, USA) 


\section{Figure 1}

Sex-specific effect of PPAR $\alpha$ deficiency on weight gain after high-fat feeding. PPAR $\alpha^{-/-}$apoE $^{-/-}$(open symbols) and PPAR $\alpha^{+/+} \mathrm{apoE}^{-/-}$(filled symbols) mice were started on a Western diet at the age of 2 months (week 0 ) and weighed every 2 weeks. (a) Triangles represent males and $(\mathbf{b})$ circles represent females. ${ }^{A} P=0.0002 \mathrm{vs}$. PPAR $\alpha^{+/+}$apoE ${ }^{-/-}$. B $P<0.0001$ vs. PPAR $\alpha^{+/+}$apoE $E^{-/-}$. For a, $n=19$ at each time point for $\mathrm{PPAR}^{+/+} \mathrm{apoE}^{-/-}$ males and $n=27$ for PPAR $\alpha^{-/-}$apoE $E^{-/-}$males. For $\mathbf{b}, n=23$ for PPAR $\alpha^{+/+}$apoE $E^{-/-}$females and $n=27$ for PPAR $\alpha^{-/-}$apoE $^{-/-}$females

with an oligo-dT primer. PCR was performed with the GeneAmp 5700 Sequence Detection System using the SYBR green dye kit (Applied Biosystems, Foster City, California, USA). Each assay included a negative control using RNA not subjected to reverse transcription. The following primers were used: LPL: 5' CAGCAAGACCTTCGTGGTGA 3' (forward) and 5' GTACAGGGCGGCCACAAGT 3' (reverse); CD36: 5' CAAGCTCCTTGGCATGGTAGA $3^{\prime}$ (forward) and $5^{\prime}$ TGGATTTGCAAGCACAATATGAA 3' (reverse); ACO: $5^{\prime}$ ATTCTCACAGCAGTGGGATTCC $3^{\prime}$ (forward) and $5^{\prime}$ TCTGCAGCATCATAACAGTGTTCTC $3^{\prime}$ (reverse); MCP-1: $5^{\prime}$ CAGCCAGATGCAGTTAACGC $3^{\prime}$ (forward) and $5^{\prime}$ GCCTACTCATTGGGATCATCTTG 3' (reverse); GAPDH: 5' GGCAAATTCAACGGCACAGT 3' (forward) and 5' CGCTCCTGGAAGATGGTGAT 3' (reverse). Product specificity was verified by running products on an agarose gel and by subjecting products to a heat-dissociation protocol. Messenger RNA levels were expressed as a percentage of GAPDH mRNA levels, which were not significantly different between genotypes.

Glucose-tolerance and insulin-tolerance tests. Studies were performed as described (28). For several days before each study, mice were accustomed to handling. Glucose-tolerance testing preceded insulin-tolerance testing by at least 1 week. Both were performed following an overnight fast, accounting for the lower fasting glucose levels (seen in Figure 8a) as compared with those (seen in Figure 2) which followed a 4-hour fast. Mice
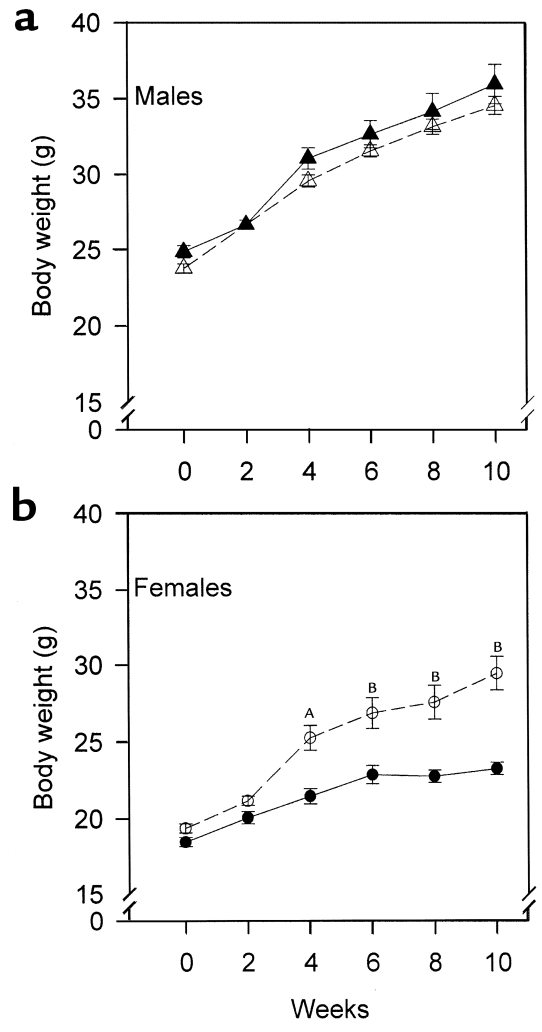

received an intraperitoneal injection of $10 \% \mathrm{D}$-glucose ( $1 \mathrm{~g} / \mathrm{kg}$ body weight) for glucose-tolerance testing, and an intraperitoneal injection of human regular insulin (Eli Lilly and Co., Indianapolis, Indiana, USA) at a dose of $0.75 \mathrm{U} / \mathrm{kg}$ body weight for insulin-tolerance testing. Tail vein blood $(5-10 \mu \mathrm{l})$ was assayed for glucose at 0 , 30,60 , and 120 minutes.

Hyperinsulinemic clamp. Clamp experiments were performed exactly as described previously (29). After placement of a double-lumen catheter, $3-\left[{ }^{3} \mathrm{H}\right]$ glucose was administered as a priming dose followed by an infusion of $0.04 \mu \mathrm{Ci} /$ minute for a 1 -hour control period. Tail vein

Table 1

LPL enzyme activity in Western diet-fed mice

\begin{tabular}{|c|c|c|c|c|}
\hline & WY-14,643 & $\mathrm{PPAR}^{+/+} \mathrm{apoE}^{-/-}$ & $\mathrm{PPAR}^{-/-} \mathrm{apoE}^{-/-}$ & $P$ value \\
\hline $\begin{array}{l}\text { Heparin-releasable } \\
\text { macrophage activity } \\
\text { (nmol/h/mg protein) }\end{array}$ & No & $\begin{array}{c}5.77 \pm 0.3 \\
\quad(12)\end{array}$ & $\begin{array}{c}5.84 \pm 0.2 \\
(12)\end{array}$ & 0.8478 \\
\hline $\begin{array}{l}\text { Postheparin plasma activity } \\
(\mu \mathrm{mol} / \mathrm{h} / \mathrm{ml})\end{array}$ & No & $\begin{array}{l}191 \pm 29 \\
(16)\end{array}$ & $\begin{array}{l}158 \pm 25 \\
(12)\end{array}$ & 0.4161 \\
\hline $\begin{array}{l}\text { Postheparin plasma activity } \\
(\mu \mathrm{mol} / \mathrm{h} / \mathrm{ml})\end{array}$ & Yes & $\begin{array}{c}262 \pm 7 \\
(3)\end{array}$ & $\begin{array}{c}168 \pm 14 \\
(3)\end{array}$ & 0.0017 \\
\hline
\end{tabular}

Data are expressed as mean \pm SEM. Thioglycolate-elicited macrophages were from Western diet-fed mice not receiving the PPAR $\alpha$ agonist $W Y$ - 14,643 . Post heparin plasma LPL activity was determined in mice eating the Western diet alone and in mice after 1 week of eating Western diet supplemented with $0.1 \%$ WY14,643. Parentheses indicate values for $n$. For macrophage LPL activity, $n$ represents the number of culture wells containing macrophages that were pooled from four different animals per genotype. For postheparin plasma LPL activity, $n$ represents the number of different animals injected with heparin. The relatively high variance for plasma activity from animals not treated with WY-14,643 is due to pooling of data from assays of several different groups of animals performed at different times. None of the individual assays of animals not treated with the agonist revealed statistically significant differences between genotypes. $P$ values were calculated by two-tailed $t$ test. 
a

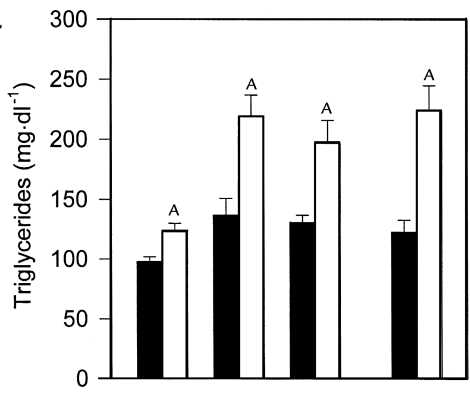

b

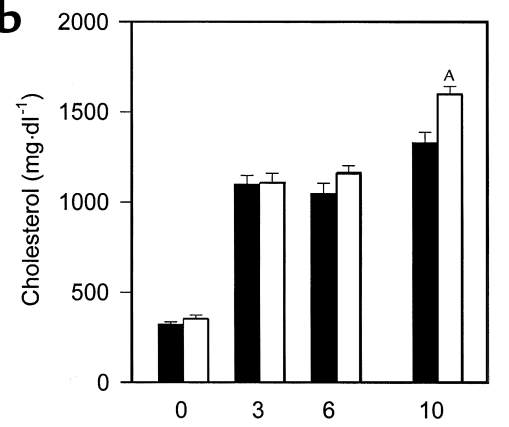

C

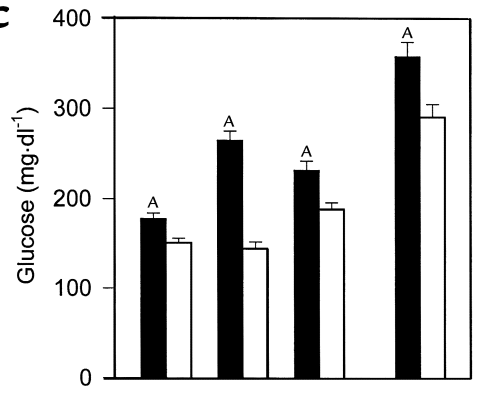

d

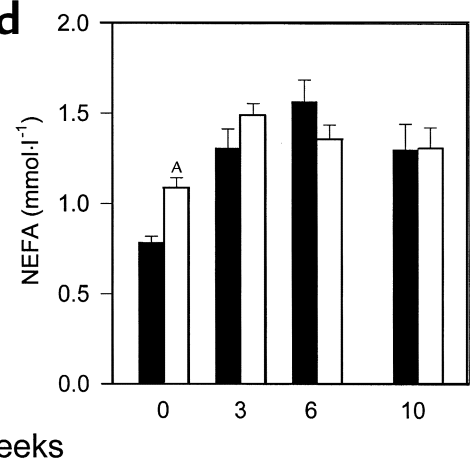

Figure 2

Serum values in PPAR $\alpha^{+/+} a p o E^{-/-}$mice (filled bars) and PPAR $\alpha^{-/}$apoE $E^{-/-}$littermates (open bars) after a 4-hour fast. Serum was obtained in animals at the age of 8 weeks on a chow diet (week 0 ). Mice were started on a Western-type diet containing $0.15 \%$ cholesterol and providing $42 \%$ calories as fat, then blood drawing was repeated at weeks 3,6 , and 10 . Samples were assayed for triglycerides (a), cholesterol (b), glucose (c), and NEFA (d) the same day of sample collection. Bars, mean \pm SEM for 27-57 mice measured in eight separate experiments over 18 months. ${ }^{A} P<0.01$ with exact $P$ values for several comparisons given in the text. glucose specific activity was determined at 45, 52, and 60 minutes to verify steady-state conditions. An insulin infusion (regular human; Eli Lilly and Co.) was started with an infusion of dextrose $(25 \%)$ that was varied to maintain the blood glucose at $120 \mathrm{mg} / \mathrm{dl}$ for at least 90 minutes of the experimental period. $3-\left[{ }^{3} \mathrm{H}\right]$ glucose infusion was maintained, and $3-\left[{ }^{3} \mathrm{H}\right]$ glucose was added to the $25 \%$ dextrose infusion to approximate the glucose specific activity in the blood at the end of the control period. Specific activity in blood samples was determined 10, 20, and 30 minutes before and at the end of the experimental period. The glucose infusion rate was stable for at least 30 minutes before the first specificactivity determination. Both blood glucose and glucose specific activity were at steady state during these sampling periods. The rate of appearance of glucose $\left(R_{a}\right)$, which is equal to glucose utilization $\left(R_{d}\right)$ at steady state, was determined by dividing the infusion rate of labeled glucose by the specific activity at the same time. Endogenous glucose production was determined by subtracting the unlabeled glucose infusion rate from $R_{a}$.
Blood pressure determinations. Systolic blood pressure was measured noninvasively in conscious mice using a tail-cuff system ( RTBP2005; Kent Scientific, Litchfield, Connecticut, USA). Mice were habituated to handling and placement in the blood pressure system for several days. To optimize the pulse signal, mice were heated to $38^{\circ} \mathrm{C}$ during each session. Five to eight measurements were recorded for each mouse at each session. Blood pressure results represent the mean of two or three sessions for each mouse on consecutive days.

\section{Results}

Effects of high-fat feeding on body weight. Mice were started on a high-fat, cholesterol-containing diet at the age of 8 weeks. In males, weight gain associated with high-fat feeding was not affected by PPAR $\alpha$ genotype (Figure 1a). There was a genotype effect on weight gain in females (Figure 1b). PPAR $\alpha^{-/-}$apoE ${ }^{-/-}$females (open circles) gained more weight than their PPAR $\alpha^{+/+}$apoE $/$littermates with high-fat feeding. By week 10, female PPAR $\alpha^{-/}$apoE $^{-/-}$weighed $27 \%$ more than female

Table 2

Endogenous glucose production and insulin responsiveness in Western diet-fed mice

\begin{tabular}{|c|c|c|c|}
\hline & PPAR $\alpha^{+/+}$apoE $^{-/-}$ & PPAR $\alpha^{-/-}$apoE $^{-/-}$ & $P$ value \\
\hline $\begin{array}{l}\text { Basal } R_{a} \\
(\mathrm{mg} / \mathrm{kg} / \mathrm{min})\end{array}$ & $14.7 \pm 1.9$ & $10.0 \pm 1.6$ & 0.1073 \\
\hline $\begin{array}{l}\text { Clamp } R_{d} \\
(\mathrm{mg} / \mathrm{kg} / \mathrm{min})\end{array}$ & $46.8 \pm 11.0$ & $46.2 \pm 7.4$ & 0.9654 \\
\hline $\begin{array}{l}\text { Endogenous glucose production } \\
(\mathrm{mg} / \mathrm{kg} / \mathrm{min})\end{array}$ & $5.1 \pm 1.1$ & 0 & 0.0286 \\
\hline
\end{tabular}

Data are expressed as mean \pm SEM. Tracer-determined rates of glucose utilization were performed at steady state in four equal-weight mice of each genotype. Endogenous glucose production was calculated by subtracting the glucose infusion rate from steady-state $R_{a}$ during the clamp and was 0 for each of the $\mathrm{PPAR}^{-/-}$apoE $\mathrm{E}^{-/-}$mice. $P$ values were calculated by two-tailed $t$ test for basal $R_{a}$ and clamp $R_{d}$ and by Mann-Whitney rank sum test for glucose production. 


\section{Figure 3}

High-resolution size-exclusion chromatography profile of serum triglycerides (a) and cholesterol (b) from PPAR $\alpha^{-/-}$apoE $E^{-/-}$mice (open symbols, broken line) and $\mathrm{PPAR}^{+/+} \mathrm{apoE}^{-/-}$littermates (filled symbols, solid line). Serum samples from eight males of each genotype eating a Western-type diet for 6 weeks were pooled, separated by chromatography, and individual fractions were assayed for lipid content. The profile is representative of four independent lipoprotein profile comparisons performed in different cohorts of mice.

$\mathrm{PPAR}^{+/+} \mathrm{apoE}^{-/-}$mice $(P<0.0001)$. Food intake was unaffected by PPAR $\alpha$ genotype. Single-knockout PPAR $\alpha$ female (but not male) mice eating chow diets are known to develop obesity with aging (30).

Fasting serum chemistries. For all serum measurements, values tended to be higher in males, but genotype effects were the same in both sexes so data from males and females are presented together. Fasting triglycerides (Figure 2a) were significantly higher in $\mathrm{PPAR}^{-/-} \mathrm{apoE}^{-/-}$mice than PPAR $\alpha^{+/+} \mathrm{apoE}^{-/-}$mice at baseline (week 0 ) and remained significantly higher at 3,6 , and 10 weeks of high-fat feeding. Cholesterol levels (Figure $2 \mathrm{~b}$ ) were the same in PPAR $\alpha^{-/-} \mathrm{apoE}^{-/-}$and $\mathrm{PPAR \alpha}^{+/+} \mathrm{apoE}^{-/-}$on a chow diet (week 0 ) and increased threefold in both genotypes with cholesterol feeding by 3 weeks. Cholesterol levels were $10 \%$ higher in PPAR $\alpha^{-/}$-apoE ${ }^{-/-}$mice at 6 weeks and $20 \%$ higher at 10

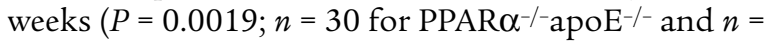
29 for $\left.\mathrm{PPAR}^{+/+} \mathrm{apoE}^{-/-}\right)$.

Fasting glucose (Figure 2c) was 18\% lower in PPAR $\alpha^{-/-}$apoE $^{-/-}$mice compared with PPAR $\alpha^{+/+} \mathrm{apoE}^{-/-}$ mice at baseline $(P=0.0006)$. High-fat feeding increased glucose levels in both genotypes, but levels

a

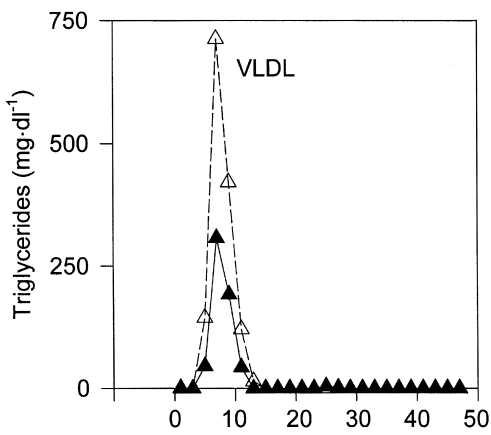

b

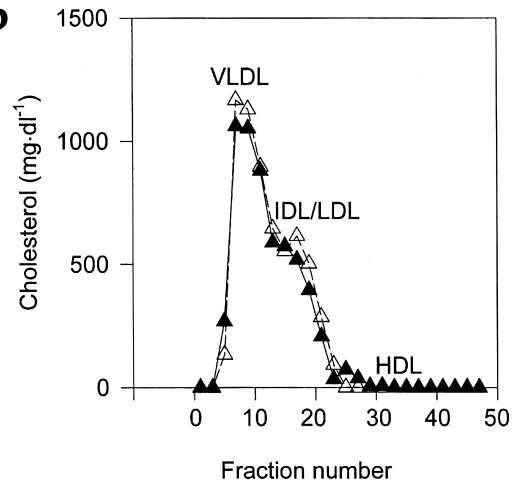

a

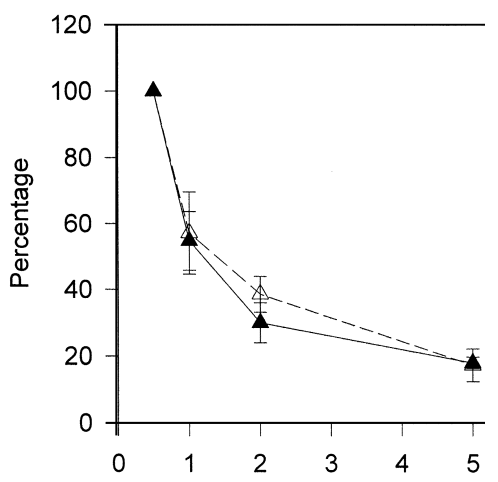

b

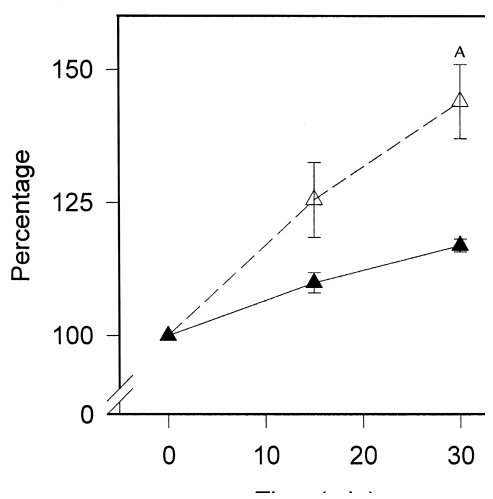

were significantly lower at each time point in PPAR $\alpha^{-/-}$ mice. After 10 weeks on the Western diet, glucose levels were $23 \%$ lower in PPAR $\alpha^{-/}$apoE $^{-/-}$mice $(P=0.0022$; $n=32$ for PPAR $\alpha^{-/-}$and $n=38$ for PPAR $\alpha^{+/+}$). Insulin levels were $0.25 \pm 0.03 \mathrm{ng} / \mathrm{ml}$ in PPAR $\alpha^{-/}-\mathrm{apoE}^{-/-}$mice $(n=15)$ and $0.55 \pm 0.08 \mathrm{ng} / \mathrm{ml}$ in PPAR $\alpha^{+/+} \mathrm{apoE}^{-/-}$mice $(n=17)$ at the 10 -week time point $(P=0.0036)$, suggesting that lower glucose levels in PPAR $\alpha$-null mice reflect enhanced insulin sensitivity compared with their wild-type littermates.

Fasting NEFA levels (Figure 2d) were 39\% higher in PPAR $\alpha$-null mice at baseline (week $0, P<0.0001 ; n=50$ for $\mathrm{PPAR}^{-/-} \mathrm{apoE}^{-/-}$and $n=42$ for PPAR $\alpha^{+/+} \mathrm{apoE}^{-/-}$). This genotype-specific difference was lost with high-fat feeding (compare weeks 3, 6, and 10 with week 0 in Figure 2d).

Lipoprotein characterization and metabolism in PPAR $\alpha^{+/+} a p o E^{-/-}$and PPAR $\alpha^{-/-}$apo $E^{-/-}$mice. Size exclusion chromatography of lipoproteins (Figure 3) from

\section{Figure 4}

Lipoprotein metabolism studies in PPAR $\alpha^{-/-} \mathrm{apoE}^{-/-}$mice (open symbols, broken line) and PPAR $\alpha^{+/+}$apoE - $^{-/}$littermates (filled symbols, solid line). (a) For the VLDL clearance data high-fat fed mice were injected with radiolabeled VLDL that was synthesized in vivo by administering $\left[9,10-{ }^{3} \mathrm{H}\right]$ palmitic acid in corn oil to $P P A R \alpha^{+/+} a p o E^{-/-}$mice. After injection of radiolabeled VLDL at time 0 , mice underwent venipuncture at 0.5 , $1,2,5$, and 20 minutes. Data are expressed as the percentage of radioactivity at the 0.5 -minute time point. Data from 20 minutes were identical to those at 5 minutes and are excluded for clarity; $n=4$ for each genotype. The same results were seen in two independent experiments. (b) For the triglyceride production data, fasting triglyceride levels were determined at time 0 , mice were injected with Triton WR 1339 to inhibit systemic lipolysis, and venipuncture was performed at 15 and 30 minutes. Data are expressed as the percentage of the fasting triglyceride levels (mean triglycerides at time 0 were $129 \mathrm{mg} / \mathrm{dl}$ for PPAR $\alpha^{+/+} \mathrm{apoE}^{-/-}$and $236 \mathrm{mg} / \mathrm{dl}$ for PPAR $\alpha^{-/-} \mathrm{apoE}^{-/-}$in this experiment). ${ }^{A} P=0.0165 \mathrm{vs}$. PPAR $\alpha^{+/+} \mathrm{apoE}^{-/-} ; n=4$ for each genotype. The same results were seen in two independent experiments. 


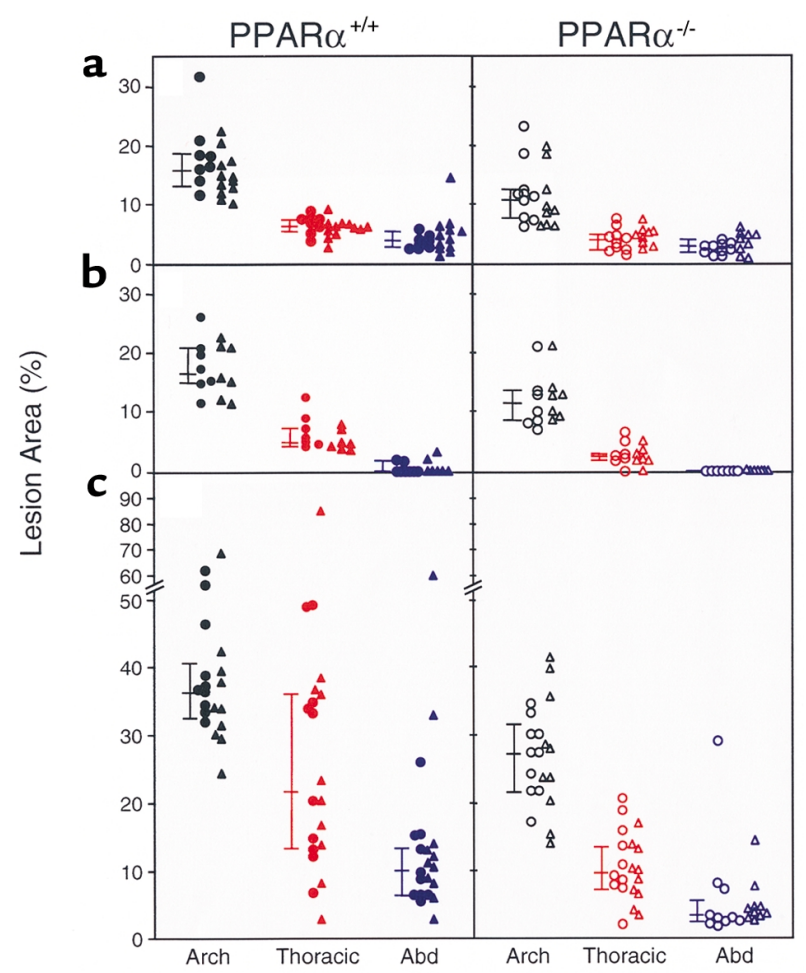

male mice fed a Western diet for 6 weeks showed that elevated triglycerides in PPAR $\alpha^{-/}$apoE ${ }^{-/-}$mice were due to elevated concentrations of VLDL (Figure 3a). PPAR $\alpha^{-/-}$apoE $^{-/-}$mice also tended to have higher levels of VLDL and IDL/LDL cholesterol (Figure 3b) that became more pronounced by 10 weeks on the Western diet (not shown). The same patterns were seen in female mice.

VLDL clearance was the same in animals of each genotype (Figure 4a). For these studies, we used radiolabeled VLDL synthesized by PPAR $\alpha^{+/+}$apoE ${ }^{-/-}$mice to focus on LPL and not particle composition. VLDL from

\section{Figure 5}

Aortic intimal lesions measured in $54 \mathrm{PPAR}^{+/+} \mathrm{apoE}^{-/-}$mice (left side of figure, filled symbols) and $53 \mathrm{PPAR}^{-/-}$apoE $\mathrm{E}^{-/-}$mice (right side of figure, open symbols) after 6 weeks ( $\mathbf{a}$ and $\mathbf{b}$ ) or 10 weeks (c) on a Western diet. Mice in a had a lower background admixture of C57BI/ 6 genes $(\sim 50 \%)$ than the mice in $\mathbf{b}$ and $\mathbf{c}(-75 \%)$. Males are indicated by triangles and females by circles. For each aorta, separate measurements of lesion area were made at the arch, thoracic aorta, and abdominal aorta. Connected bars to the left of each data set indicate the median with $25 \%$ and $75 \%$ confidence intervals. Lesion area was significantly greater in $\mathrm{PPAR}^{+/+}$than PPAR $\alpha^{-/-}$mice for each of the nine data sets (see text for $P$ values). Comparisons were made between the same aortic regions. As an example, in $\mathbf{c}$ the lesion area at the thoracic aorta in PPAR $\alpha^{+/+}$mice (indicated by the filled red symbols on the left side) was significantly greater than the lesion area at the thoracic aorta in PPAR $\alpha^{-/-}$mice (indicated by the open red symbols on the right side).

PPAR $\alpha^{-/}$apoE $^{-/-}$animals would be expected to have decreased clearance in part due to an elevated apoCIII content. Triglyceride production was increased in $\mathrm{PPAR}^{-/-} \mathrm{apoE}^{-/-}$animals (Figure $4 \mathrm{~b}$ ), providing an explanation for the elevated VLDL concentrations seen in these mice (Figure 3).

Lesion extent in Western diet-fed mice. Atherosclerosis was quantified by pinning aortas en face and measuring the percentage of intimal surface affected by atheroma at three different sites in each animal: aortic arch, thoracic aorta, and abdominal aorta. Figure 5 shows lesion extent in $54 \mathrm{PPAR}^{+/+} \mathrm{apoE}^{-/-}$mice and 53 PPAR $\alpha^{-/-}$apoE $E^{-/-}$mice studied after either 6 weeks (Figure 5 , $a$ and b) or 10 weeks (Figure 5 c) on the Western diet. Littermates with the same $\mathrm{C} 57 \mathrm{Bl} / 6$ background of approximately $75 \%$ were used for Figure $5, \mathrm{~b}$ and c. Figure 5 a shows data from mice with a C57Bl/6 background of approximately $50 \%$.

Despite having $20 \%$ higher serum cholesterol than $\mathrm{PPAR}^{+/+}$apoE ${ }^{-/-}$littermates, $\mathrm{PPAR}^{-/-} \mathrm{apoE}^{-/-}$mice fed the Western diet for 10 weeks had less atherosclerosis (Figure 5c). Median lesion area was 25\% lower at the

\section{Figure 6}

Detection of PPAR $\alpha$ protein by immunocytochemistry in atherosclerotic lesions of PPAR $\alpha^{+/+} \mathrm{apoE}^{-/-}$mice (left) but not $\mathrm{PPAR}^{-/-} \mathrm{apoE}^{-/-}$mice (right). Nuclear staining was detected throughout the neointima. In other experiments (not shown), serial sections showed these PPAR $\alpha$-positive cells to also react with an anti-macrophage Ab. Arrows indicate additional positive staining in elongated cells associated with the media. In other experiments (not shown), serial sections showed these PPAR $\alpha$-positive cells to react also with an anti-smooth muscle $\alpha$ actin Ab. These sections were from mice fed a Western diet for 6 weeks. The same results were seen in multiple sections from three different PPAR $\alpha^{+/+}$and four different $\mathrm{PPAR}^{-/-}$mice. No signals were seen in PPAR $\alpha^{+/+}$lesions when slides were subjected to the immunocytochemical protocol with the omission of the primary $\mathrm{Ab}$ (not shown).
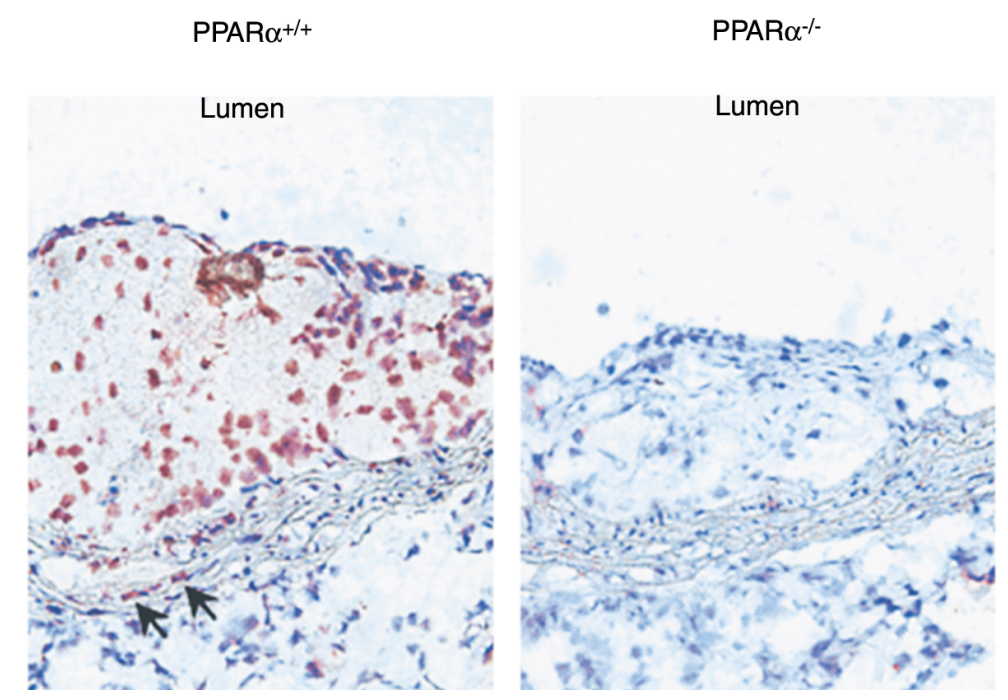


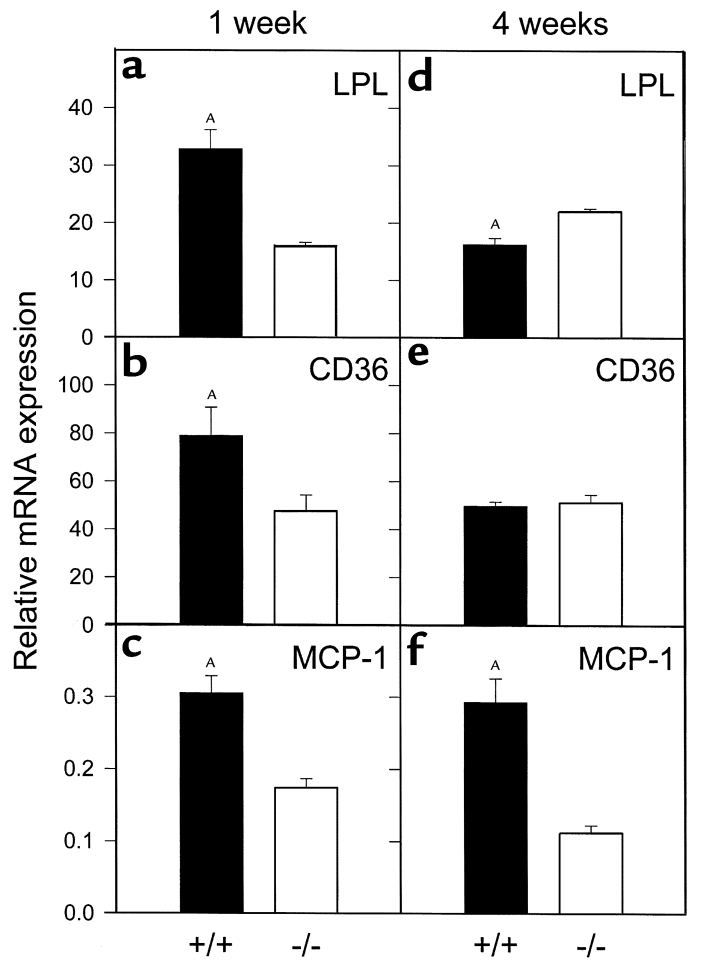

arch $(P<0.0001), 54 \%$ lower at the thoracic aorta $(P<$ $0.0001)$, and $65 \%$ lower at the abdominal aorta $(P<$ $0.0001)$ in $\mathrm{PPAR}^{-/} \mathrm{apoE}^{-/-}$compared with $\mathrm{PPAR}^{+/+} \mathrm{apoE}^{-/-}$mice. As expected, overall lesion extent was less after 6 weeks on the Western diet, but PPAR genotype effects were the same (Figure $5 \mathrm{~b}$ ). Lesion area at 6 weeks was $31 \%$ lower at the arch $(P=$ $0.0038), 60 \%$ lower at the thoracic aorta $(P<0.0001)$, and $100 \%$ lower at the abdominal aorta $(P=0.0385)$ in the PPAR $\alpha$-null animals. The same genotype effects on atherosclerosis were seen in mice with a lower admixture of $\mathrm{C} 57 \mathrm{Bl} / 6$ background genes (Figure 5a). At 6 weeks, lesion area was $34 \%$ lower at the arch $(P=$ $0.0017), 34 \%$ lower at the thoracic aorta $(P<0.0001)$, and $29 \%$ lower at the abdominal aorta $(P=0.0316)$ in PPAR $\alpha$-null animals.

Immunocytochemistry of vascular lesions. To confirm that PPAR $\alpha$ was present in the atherosclerotic lesions of PPAR $\alpha^{+/+}$apoE ${ }^{-/-}$mice, immunocytochemical studies were performed (Figure 6). Immunostaining for PPAR $\alpha$ was prominent in nuclei throughout the lipid-filled neointima of $\mathrm{PPAR}^{+/+} \mathrm{apoE}^{-/-}$lesions. Some endothelial cells showed staining for PPAR $\alpha$. In addition, nuclear

\section{Figure 8}

Enhanced glucose tolerance and insulin responsiveness in PPAR $\alpha$-deficient mice. Mice were started on a Western diet at the age of 8 weeks and studied 4 weeks later. (a) Animals were injected with $1 \mathrm{~g}$ D-glucose/ $\mathrm{kg}$ body weight, then tail-vein blood glucose was assayed at various times. ${ }^{A} P=0.0003$ vs. $P P A R \alpha^{-/} \mathrm{apoE}^{-/-} ;{ }^{\mathrm{B}} P=0.0162 \mathrm{vs}$. $\mathrm{PPAR}^{-/-} \mathrm{apoE}^{-/-} ; n=5$ for each genotype. (b) Mice were injected with $0.75 \mathrm{U}$ insulin $/ \mathrm{kg}$ body weight, then tail vein blood was obtained. $P P A R \alpha^{+/+} a p o E^{-/-}$animals are represented by filled symbols and PPAR $\alpha^{-/}$apoE $E^{-/-}$by open symbols. ${ }^{A} P=0.0124 \mathrm{vs}$. PPAR $\alpha^{-/-}$apoE ${ }^{-/-}$; $\mathrm{B} P=0.0435$ vs. PPAR $\alpha^{-/-} \mathrm{apoE}^{-/-} ; n=8$ for each genotype.

\section{Figure 7} cells, respectively.

Aortic expression of LPL, CD36, and MCP-1. PPAR $\alpha^{+/+} \mathrm{apoE}^{-/-}$(filled bars) and PPAR $\alpha^{-/-}$apoE ${ }^{-/-}$(open bars) mice were fed a Western diet plus $0.1 \%$ WY-14,643 for 1 week or 4 weeks, followed by isolation of RNA from the entire aorta and analysis by quantitative RT-PCR. Data are presented relative to GAPDH mRNA levels in the same samples. (a) ${ }^{A} P=0.0002$, (b) ${ }^{A} P=0.0437,(\mathbf{c}){ }^{A} P=0.0002$, (d) ${ }^{A} P=0.0041$ (f) ${ }^{A} P=0.0006$, all versus $P P A R \alpha^{-/-}$apoE $E^{-/-}$. Hepatic ACO mRNA in the same animals was 10.7-fold and 4.3-fold higher in PPAR $\alpha^{+/+}$apoE $E^{-/-}$as compared with PPAR $\alpha^{-/-} \mathrm{apoE}^{-/-}$mice at 1 and 4 weeks, respectively (both $P<0.001$ ).

staining was detected in the media within elongated, spindle-shaped cells (arrows, Figure 6) resembling smooth muscle cells. Parallel staining (not shown) using an anti-macrophage $\mathrm{Ab}$ (MAC-3; BD Pharmingen, San Diego, California, USA) and an anti-smooth muscle $\alpha$ actin Ab (Zymed, South San Francisco, California, USA) confirmed that the PPAR $\alpha^{+/+}$-positive cells in the neointima and media were macrophages and smooth muscle

Plasma and macrophage LPL enzyme activity. PPAR $\alpha$ may regulate LPL expression, and LPL in the vasculature can promote atherosclerosis. The lack of a difference in VLDL clearance (Figure 4a) suggests that PPAR $\alpha$ genotype does not have a major effect on LPL activity in these mice. Heparin-releasable activity was identical in thioglycolate-elicited peritoneal macrophages from $\mathrm{PPAR}^{+/+} \mathrm{apoE}^{-/-}$mice and PPAR $\alpha^{-/-} \mathrm{apoE}^{-/-}$mice (Table 1). There was also no significant difference in postheparin plasma LPL activity between these animals (Table 1). However, these animals were studied in the fasting

a

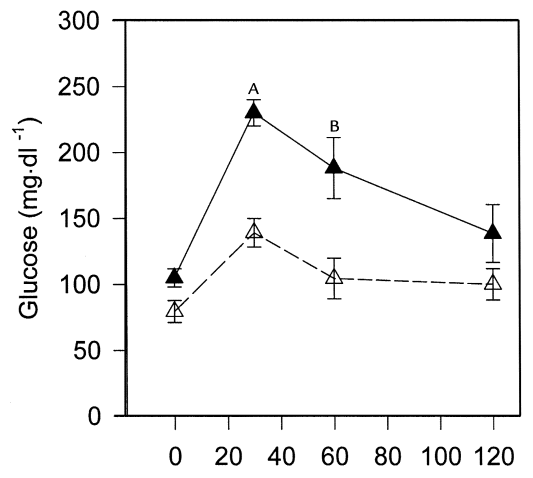

b

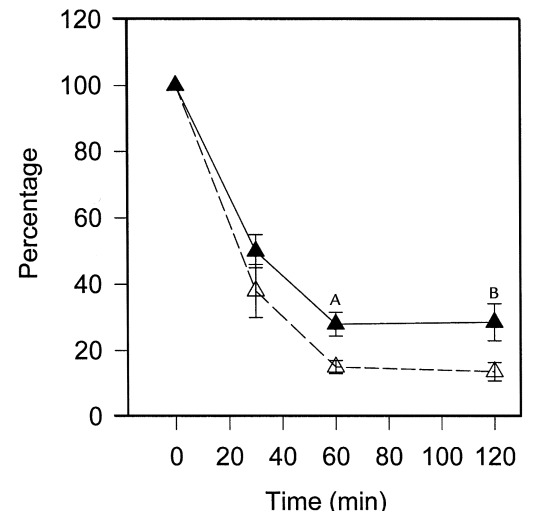




\section{Figure 9}

Lower blood pressures in PPAR $\alpha$-deficient mice fed a Western diet. PPAR $\alpha^{+/+} a p o E^{-/-}$mice (filled bars) and $\mathrm{PPAR}^{-/-} \mathrm{apoE}^{-/-}$mice (open bars) were started on a Western diet at the age of 8 weeks, and systolic blood pressures were measured at the tail 4 weeks later. Five to eight determinations were performed for each mouse at each session after habituating each animal to the blood pressure apparatus for several days. The final pressure was recorded as the mean of two or three sessions for each mouse. Data represent measurements for both sexes. (a) $n=17$ for $\mathrm{PPAR}^{+/+}$and $n=25$ for PPAR $\alpha^{-/-}$. (b) $n=17$ for PPAR $\alpha^{+/+}$ and $n=29$ for PPAR $\alpha^{-/-}$. AP $=0.0336$ vs. PPAR $\alpha^{+/+}$.

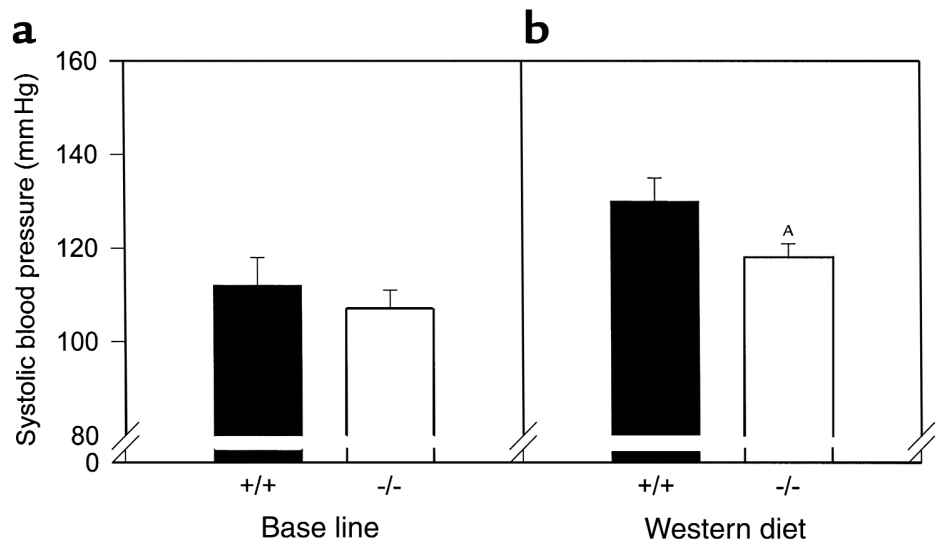

state and natural PPAR $\alpha$ agonists provided by feeding might alter LPL expression.

To determine if PPAR activation can affect LPL in these animals, mice were fed Western diet containing $0.1 \%$ WY-14,643, a potent PPAR $\alpha$ agonist. After 1 week, postheparin plasma LPL activity was significantly higher in PPAR $\alpha^{+/+}$mice (Table 1). However, VLDL clearance after 1 week of dietary supplementation with WY-14,643 was virtually identical in $\mathrm{PPAR}^{+/+} \mathrm{apoE}^{-/-}$and PPAR $\alpha^{-/-} \mathrm{apoE}^{-/-}$mice $(n=4$ per genotype, data not shown).

Aortic gene expression. Consistent with our finding of greater postheparin LPL enzyme activity in PPAR $\alpha$ agonist-treated PPAR $\alpha^{+/+}$mice, LPL mRNA levels (normalized to GAPDH) were significantly higher in the aortas of PPAR $\alpha^{+/+}$apoE $E^{-/-}$as compared with $\mathrm{PPAR}^{-/-} \mathrm{apoE}^{-/-}$mice after 1 week of agonist treatment (Figure $7 \mathrm{a}$ ). At the same time point, aortic message levels for CD36 and MCP-1 were also higher in agonist-treated PPAR $\alpha^{+/+}$mice (Figure 7, b and c). This difference was sustained at 4 weeks of agonist treatment for MCP-1 (Figure 7f). However, CD36 mRNA levels were the same in both genotypes (Figure 7e), and LPL mRNA levels were significantly lower in PPAR $\alpha^{+/+}$ mice after 4 weeks of WY-14,643 (Figure 7d). In the same animals, hepatic ACO (a known PPAR $\alpha$-responsive gene) mRNA levels were 10.7-fold higher in $\mathrm{PPAR}^{+/+} \mathrm{apoE}^{-/-}$as compared with $\mathrm{PPAR} \alpha^{-/-} \mathrm{apoE}^{-/-}$ mice $(P=0.0004)$ at 1 week and 4.3 -fold higher in PPAR $\alpha^{+/+}$apoE $^{-/-}$as compared with PPAR $\alpha^{-/-} \mathrm{apoE}^{-/-}$ mice $(P=0.0002)$ at 4 weeks.

Glucose metabolism. To determine if a difference in insulin sensitivity is present before the time points showing differences in atherosclerosis, we performed glucose-tolerance and insulin-tolerance tests in separate cohorts of animals after 4 weeks of high-fat feeding. PPAR $\alpha^{-/-} \mathrm{apoE}^{-/-}$mice had lower glycemic excursions than PPAR $\alpha^{+/+}$apoE $/ /-$mice at 30 minutes $(P=$ $0.0003)$ and 60 minutes $(P=0.0162)$ after a glucose challenge (Figure 8a). PPAR $\alpha^{-/-} \mathrm{apoE}^{-/-}$mice became more hypoglycemic than $\mathrm{PPAR}^{+/+} \mathrm{apoE}^{-/-}$mice in response to exogenous insulin (Figure $8 \mathrm{~b}$ ). Hyperinsulinemic clamp experiments demonstrated that the lower glucose levels were due to the effects of insulin on endogenous glucose production (Table 2).

Blood pressure determinations. Since hypertension is associated with insulin resistance and promotes atherosclerosis, we measured blood pressures in these mice. There was no effect of PPAR $\alpha$ on systolic blood pressure at baseline (Figure 9a). Blood pressure increased in both genotypes after 4 weeks of high-fat feeding (Figure 9b), but were $10 \%$ lower in PPAR $\alpha^{-/-} \mathrm{apoE}^{-/-}$mice as compared with $\mathrm{PPAR} \alpha^{+/+}$apoE ${ }^{-/-}$mice $(P=0.0336 ; n=29$ for $\mathrm{PPAR}^{-/-} \mathrm{apoE}^{-/-}$and $n=17$ for $\left.\mathrm{PPAR}^{+/+} \mathrm{apoE}^{-/-}\right)$.

\section{Discussion}

In this study, we show that apoE-null mice are relatively protected from diet-induced insulin resistance and atherosclerosis by the genetic absence of the ligand-activated transcription factor PPAR $\alpha$. Mice deficient in PPAR $\alpha$ had higher concentrations of atherogenic lipoproteins but more insulin sensitivity, lower blood pressures, and fewer intimal lesions. These results were unexpected since PPAR $\alpha$ agonists decrease clinical events in humans with vascular disease.

To our knowledge, humans with complete PPAR $\alpha$ deficiency have not yet been described. However, a leucine to valine missense mutation at residue 162 of the PPAR $\alpha$ molecule is common in different ethnic groups (31-33). This mutation is in the DNA-binding domain and has functional consequences in transactivation assays (33). Humans with this mutation, like mice with PPAR $\alpha$ deficiency, have higher concentrations of atherogenic lipoproteins. The current results raise the possibility that dyslipidemia in these individuals may not have the same adverse consequences as dyslipidemia in those with wild-type PPAR $\alpha$.

PPAR $\alpha$ deficiency in mice may decrease atherosclerosis either through systemic or vessel wall effects. In terms of systemic effects, the liver is a source of several PPAR $\alpha$ responsive molecules implicated in atherosclerosis, including fibrinogen, plasminogen activator inhibitor-1 (PAI-1), and apoAI. Genetic modulation of fibrinogen (34) or PAI-1 (35) does not appear to affect lesion size in apoE-null mice. Overexpression of apoAI decreases ath- 
erosclerosis in apoE-null mice (36), and apoAI levels are known to be elevated in PPAR $\alpha$-null mice (37). We did not measure apoAI levels in our experiments. As expected, HDL levels in these Western diet-fed mice were extremely low regardless of genotype, making it unlikely that HDL has a major effect on the vascular phenotype.

Glucose levels were significantly lower in PPAR $\alpha$-null animals, providing another potential systemic etiology for less atherosclerosis in these mice. In humans, glucose levels are strongly and positively associated with ischemic heart disease even among nondiabetics (38). In mice, experimental diabetes can be associated with increased atherosclerosis $(39,40)$. However, dyslipidemia rather than hyperglycemia may be responsible for this effect (41).

Blood pressures were lower in PPAR $\alpha$-null animals, a systemic effect that might explain why animals with higher concentrations of atherogenic lipoproteins would have fewer lesions. Independent of lipid levels, apoE-null mice deficient in endothelial nitric oxide synthase have higher blood pressures and more atherosclerosis (42). PPAR $\alpha$-null mice were protected from insulin resistance, which might explain the lower blood pressures in these mice. Insulin infusion does not dilate blood vessels in subjects with insulin resistance due to impaired nitric oxide production by insulin-resistant endothelial cells (7). Endothelial expression of Akt, a mediator of insulin signaling, increases nitric oxide production and promotes vasodilation (43).

The absence of PPAR $\alpha$ in the vessel wall may have contributed to the vascular phenotype. PPAR $\alpha$ can increase LPL activity. Vascular wall LPL promotes the retention of atherogenic lipoproteins and has been shown to be proatherogenic by independent groups using different mouse models (12, 44-46). Using short-term administration of a potent PPAR $\alpha$ agonist (WY-14,643) as a tool to mimic activation of PPAR $\alpha$ that might be expected to occur with feeding, we found higher levels of plasma postheparin LPL enzyme activity and higher levels of aortic mRNA for LPL in PPAR $\alpha$ mice. Message levels for the proatherogenic molecules CD36 (13) and MCP-1 (47) were also higher in PPAR $\alpha^{+/+}$as compared with PPAR $\alpha^{-/-}$mice at a time point when large differences in atherosclerosis would not be expected. These observations do not prove that PPAR $\alpha$ in the vessel wall is proatherogenic since systemic effects can alter vessel wall gene expression. However, they are consistent with recent data showing that WY-14,643 induces MCP- 1 synthesis by endothelial cells and that atherogenic lipids increase MCP-1 production by these cells through a PPAR $\alpha$-dependent mechanism (48).

PPAR $\alpha$ promotes fatty acid oxidation. Defects in fatty acid oxidation are known to affect glucose metabolism, and PPAR $\alpha$-null mice are prone to the development of hypoglycemia in response to stressors $(49,50)$. Our data show that these mice are protected from diet-induced insulin resistance, consistent with the notion that inhibition of fatty acid oxidation is a potential strategy for the treatment of diabetes (51). More than 30 years ago, Williamson and colleagues (52) showed that fatty acid oxidation promotes insulin resistance in the liver, a major site of PPAR $\alpha$ expression, in part by generating NADH. The availability of cytosolic NADH promotes an NADH/NADPH oxidase activity (53), a major source of superoxide generation. Superoxide anion may promote atherogenesis by multiple mechanisms, including the promotion of hypertension. PPAR $\alpha$ deficiency in the vessel wall could decrease fatty acid oxidation, leading to less production of NADH, less superoxide production, lower blood pressure, less oxidative modification of lipoproteins, and less atherosclerosis. If this scheme is true, selective antagonists of PPAR $\alpha$ acting at the vessel wall could decrease vascular disease.

\section{Acknowledgments}

This work was supported by the NIH grants HL-58427, DK-53198, the Washington University Clinical Nutrition Research Unit (DK56341), and the Washington University Diabetes Research and Training Center (DK20579). L. Zemany was supported by the Four Schools PhysicianScientist Program. We thank Jay Heinecke and Jeff Saffitz for commenting on the manuscript.

1. Howard, G., et al. 1996. Insulin sensitivity and atherosclerosis. Circulation. 93:1809-1817.

2. Kersten, S., Desvergne, B., and Wahli, W. 2000. Roles of PPARs in health and disease. Nature. 405:421-424.

3. Palmer, C.N.A., Hsu, M.-H., Griffin, K.J., Raucy, J.L., and Johnson, E.F. 1998. Peroxisome proliferator activated receptor- $\alpha$ expression in human liver. Mol. Pharmacol. 53:14-22.

4. Braissant, O., Foufelle, F., Scotto, C., Dauca, M., and Wahli, W. 1996. Differential expression of peroxisome proliferator-activated receptors: tissue distribution of PPAR- $\alpha,-\beta$, and $-\gamma$ in the adult rat. Endocrinology. 137:354-366.

5. Chinetti, G., et al. 2000. CLA-1/SR-BI is expressed in atherosclerotic lesion macrophages and regulated by activators of peroxisome proliferator-activated receptors. Circulation. 101:2411-2417.

6. Laakso, M., Edelman, S.V., Brechtel, G., and Baron, A.D. 1990. Decreased effect of insulin to stimulate skeletal muscle blood flow in obese man. A novel mechanism of insulin resistance. J. Clin. Invest. 85:1844-1852.

7. Steinberg, H.O., et al. 1997. Elevated circulating free fatty acid levels impair endothelium-dependent vasodilation. J. Clin. Invest. 100:1230-1239.

8. Schoonjans, K., et al. 1996. PPAR $\alpha$ and PPAR $\gamma$ activators direct a tissuespecific transcriptional response via a PPRE in the lipoprotein lipase gene. EMBO J. 15:5336-5348.

9. Tontonoz, P., Nagy, L., Alvarez, J.G., Thomazy, V.A., and Evans, R.M. 1998. PPAR $\gamma$ promotes monocyte/macrophage differentiation and update of oxidized LDL. Cell. 93:241-252.

10. Frohnert, B.I., Nui, T.Y., and Bernlohr, D.A. 1999. Identification of a functional peroxisome proliferator-activated responsive element in the murine fatty acid transport protein gene. J. Biol. Chem. 274:3970-3977.

11. Schoonjans, K., et al. 1995. Induction of the acyl-coenzyme A synthetase gene by fibrates and fatty acids is mediated by a peroxisome proliferator response element in the C promoter. J. Biol. Chem. 270:19269-19276.

12. Semenkovich, C.F., Coleman, T., and Daugherty, A. 1998. Effects of heterozygous lipoprotein lipase deficiency on diet-induced atherosclerosis in mice. J. Lipid Res. 39:1141-1151.

13. Febbraio, M., et al. 2000. Targeted disruption of the class B scavenger receptor CD36 protects against atherosclerotic lesion development in mice. J. Clin. Invest. 105:1049-1056.

14. Chinetti, G., et al. 2001. PPAR- $\alpha$ and PPAR- $\gamma$ activators induce cholesterol removal from human macrophage foam cells through stimulation of the ABCA1 pathway. Nat. Med. 7:53-58.

15. Rubins, H.B., et al. 1999. Gemfibrozil for the secondary prevention of coronary heart disease in men with low levels of high-density lipoprotein cholesterol. N. Engl. J. Med. 341:410-418.

16. Li, A.C., et al. 2000. Peroxisomal proliferator-activated receptor $\gamma$ ligands inhibit development of atherosclerosis in LDL receptor-deficient mice. 
J. Clin. Invest. 106:523-531.

17. Yu, H., and Nicolantonio, R. 1998. Altered nuclear protein binding to the first intron of the renin gene of the spontaneously hypertensive rat. Clin. Exp. Hypertens. 20:817-832.

18. Barroso, I., et al. 1999. Dominant negative mutations in human PPARgamma associated with severe insulin resistance, diabetes mellitus and hypertension. Nature. 402:880-883.

19. Torra, I.P., Gervois, P., and Staels, B. 1999. Peroxisome proliferator-activated receptor alpha in metabolic disease, inflammation, atherosclerosis and aging. Curr. Opin. Lipidol. 10:151-159.

20. Guerre-Millo, M., et al. 2000. Peroxisome proliferator-activated receptor alpha activators improve insulin sensitivity and reduce adiposity. J. Biol. Chem. 275:16638-16642.

21. Lee, S.S.T., et al. 1995. Targeted disruption of the $\alpha$ isoform of the peroxisome proliferator-activated receptor gene in mice results in abolishment of the pleiotropic effects of peroxisome proliferators. Mol. Cell. Biol. 15:3012-3022.

22. Zhang, S.H., Reddick, R.L., Burkey, B., and Maeda, N. 1994. Diet-induced atherosclerosis in mice heterozygous and homozygous for apolipoprotein E gene disruption. J. Clin. Invest. 94:937-945.

23. Towler, D.A., Bidder, M., Latiffe, T., Coleman, T., and Semenkovich, C.F. 1998. Diet-induced diabetes activates an osteogenic gene regulatory program in the aortas of low density lipoprotein receptor-deficient mice. J. Biol. Chem. 273:30427-30434.

24. Weinstock, P.H., et al. 1995. Severe hypertriglyceridemia, reduced high density lipoprotein, and neonatal death in lipoprotein lipase knockout mice. Mild hypertriglyceridemia with impaired very low density lipoprotein clearance in heterozygotes. J. Clin. Invest. 96:2555-2568.

25. Abdel-Fattah, G., Fernandez, M.L., and McNamara, D.J. 1995. Regulation of guinea pig very low density lipoprotein secretion rates by dietary fat saturation. J. Lipid Res. 36:1188-1198.

26. Coleman, T., et al. 1995. COOH-terminal disruption of lipoprotein lipase in mice is lethal in homozygotes, but heterozygotes have elevated triglycerides and impaired enzyme activity. J. Biol. Chem. 270:12518-12525.

27. Seip, R.L., Angelopoulos, T.J., and Semenkovich, C.F. 1995. Exercise induces human lipoprotein lipase gene expression in skeletal muscle but not adipose tissue. Am. J. Physiol. 268:E229-E236.

28. Li, B., et al. 2000. Skeletal muscle respiratory uncoupling prevents dietinduced obesity and insulin resistance in mice. Nat. Med. 6:1115-1120.

29. Marshall, B., et al. 1999. Relative hypoglycemia and hyperinsulinemia in mice with heterozygous lipoprotein lipase (LPL) deficiency: islet LPL regulates insulin secretion. J. Biol. Chem. 274:27426-27432.

30. Costet, P., et al. 1998. Peroxisome proliferator-activated receptor $\alpha$-isoform deficiency leads to progressive dyslipidemia with sexually dimorphic obesity and steatosis. J. Biol. Chem. 273:29577-29585.

31. Flavell, D.M., et al. 2000. Variation in the PPARalpha gene is associated with altered function in vitro and plasma lipid concentrations in type II diabetic subjects. Diabetologia. 43:673-680.

32. Vohl, M.C., et al. 2000. Molecular scanning of the human PPAR $\alpha$ gene: association of the L $162 \mathrm{~V}$ mutation with hyperapobetalipoproteinemia. J. Lipid Res. 41:945-952.

33. Sapone, A., et al. 2000. The human peroxisome proliferator-activated receptor alpha gene: identification and functional characterization of two natural allelic variants. Pharmacogenetics. 10:321-333.

34. Xiao, Q., et al. 1998. Fibrinogen deficiency is compatible with the development of atherosclerosis in mice. J. Clin. Invest. 101:1184-1194.

35. Sjoland, H., et al. 2000. Atherosclerosis progression in LDL receptor-defi- cient and apolipoprotein E-deficient mice is independent of genetic alterations in plasminogen activator inhibitor-1. Arterioscler. Thromb. Vasc. Biol. 20:846-852.

36. Paszty, C., Maeda, N., Verstuyft, J., and Rubin, E.M. 1994. Apolipoprotein AI transgene corrects apolipoprotein E deficiency-induced atherosclerosis in mice. J. Clin. Invest. 94:899-903.

37. Peters, J.M., et al. 1997. Alterations in lipoprotein metabolism in peroxisome proliferator-activated receptor $\alpha$-deficient mice. J. Biol. Chem. 272:27307-27312.

38. Khaw, K.-T., et al. 2001. Glycated hemoglobin, diabetes, and mortality in men in Norfolk cohort of European Prospective Investigation of Cancer and Nutrition (EPIC-Norfolk). BMJ. 322:1-6.

39. Schreyer, S.A., Wilson, D.L., and LeBoeuf, R.C. 1998 . C57BL/6 mice fed high fat diets as models for diabetes-accelerated atherosclerosis. Atherosclerosis. 136:17-24

40. Park, L., et al. 1998. Suppression of accelerated diabetic atherosclerosis by the soluble receptor for advanced glycation endproducts. Nat. Med. 4:1025-1031.

41. Reaven, P., Merat, S., Casanada, F., Sutphin, M., and Palinski, W. 1997 Effect of streptozotocin-induced hyperglycemia on lipid profiles, formation of advanced glycation endproducts in lesions, and extent of atherosclerosis in LDL receptor-deficient mice. Arterioscler. Thromb. Vasc. Biol. 17:2250-2256.

42. Knowles, J.W., et al. 2000. Enhanced atherosclerosis and kidney dysfunction in eNOS(-/-)Apoe(-/-) mice are ameliorated by enalapril treatment. J. Clin. Invest. 105:451-458.

43. Luo, Z., et al. 2000. Acute modulation of endothelial Akt/PKB activity alters nitric oxide-dependent vasomotor activity in vivo. J. Clin. Invest. 106:493-499.

44. Babaev, V., et al. 1999. Macrophage lipoprotein lipase promotes foam cell formation and atherosclerosis in vivo. J. Clin. Invest. 103:1697-1705.

45. Babaev, V., Carter, K.J., Semenkovich, C.F., Fazio, S., and Linton, M.F. 2000. Macrophage lipoprotein lipase promotes foam cell formation and atherosclerosis in LDL receptor deficient mice. J. Biol. Chem. 275:26293-26299.

46. Van Eck, M., Zimmermann, R., Groot, P.H.E., Zechner, R., and Van Berkel, T.J.C. 2000. Role of macrophage-derived lipoprotein lipase in lipoprotein metabolism and atherosclerosis. Arterioscler. Thromb. Vasc. Biol. 20:e53-e62.

47. Gu, L., et al. 1998. Absence of monocyte chemoattractant protein-1 reduces atherosclerosis in low density lipoprotein receptor-deficient mice. Mol. Cell. 2:275-281.

48. Lee, H., et al. 2000. Role for peroxisome proliferator-activated receptor alpha in oxidized phospholipid-induced synthesis of monocyte chemotactic protein- 1 and interleukin-8 by endothelial cells. Circ. Res. 15:516-521.

49. Djouadi, F., et al. 1998. A gender-related defect in lipid metabolism and glucose homeostasis in peroxisome proliferator-activated receptor $\alpha$ deficient mice. J. Clin. Invest. 102:1083-1091.

50. Kersten, S., et al. 1999. Peroxisome proliferator-activated receptor $\alpha$ mediates the adaptive response to fasting. J. Clin. Invest. 103:1489-1498.

51. Foley, J.E. 1992. Rationale and application of fatty acid oxidation inhibitors in treatment of diabetes mellitus. Diabetes Care. 15:773-784

52. Williamson, J.R., Browning, T., and Scholz, R. 1969. Control mechanisms of gluconeogenesis and ketogenesis. I. Effects of oleate on gluconeogenesis in perfused rat liver. J. Biol. Chem. 244:4607-4616.

53. Gupte, S., Rupawalla, B.A., Phillibert, D., and Wolin, M.S. 1999. Regulation of NO-elicited pulmonary artery relaxation and guanylate cyclase activity by NADH oxidase and SOD. Am. J. Physiol. 276:H1535-H1542. 